\title{
The 50s Are the New 30s: And You Can Still Have Kids due to Oocyte Cryopreservation
}

\author{
By Vera Lúcia Raposo*
}

\begin{abstract}
Women in Western societies have been progressively postponing the birth of their first child. However, the human body has not always accommodated the new professional and personal challenges women have faced. It has therefore not been uncommon for women to discover that it is simply too late for them to become pregnant. To overcome the obstacles that biology imposes on female reproduction, women have resorted to oocyte cryopreservation. This procedure was originally used by patients with a risk of becoming infertile from medical treatments. Now it is increasingly being used to expand reproductive age. Although oocyte cryopreservation presents several advantages in light of other possible reproductive options for older women, such as oocyte donation and embryo cryopreservation, it still raises many legal, medical and ethical concerns. From a medical perspective the main concerns are the risks for the woman (oocyte extraction) and for offspring (oocyte cryopreservation). Ethically it has been argued that this medical procedure is nothing but the fulfilment of a whim, at the expenses of the violation of natural boundaries to human reproduction, resulting in contra natura practices. From a juridical standpoint it is clear that there are still many questions that need to be legally solved: time limit for oocyte cryopreservation, consequences of the oocytes' holder death, lawfulness of oocyte donation (in life or after death), compensation in case of oocyte destruction, requirements of patients' informed consent and legal limitations that may prevent women from using cryopreserved oocytes. All these are issues which are addressed in the paper.
\end{abstract}

Keywords: Embryo cryopreservation, Late motherhood, Oocyte cryopreservation, Oocyte donation, Right to reproduce

\section{Late Reproduction and Oocyte Cryopreservation}

In most Western societies, many men and women have been choosing to have children progressively later in life because life expectancy has increased substantially and because professional aims have taken preference over other family goals, such as raising a family (Leridon 2004). For men, this change of priorities has not caused serious problems because male fertility extends until very late in life. For women, however, late-life reproduction is sometimes impossible because of the biological obstacles connected to female fertility.

One mechanism that is increasingly used to address women's reproductive difficulties is oocyte cryopreservation for fertility maintenance. This process operates by artificially stimulating female ovulation and preserving the oocytes obtained thereby. During a normal menstrual cycle, only one oocyte reaches maturity, whereas if a woman has been subjected to hormonal therapy, more oocytes are released. These are removed from the woman's body with a needle and evaluated for their suitability for future fertilisation. Only oocytes that are considered to be healthy are preserved for future reproductive use (The Practice Committees of the American Society for Reproductive Medicine and the Practice Committee of the Society for Assisted Reproductive Technology 2013, Argyle et al. 2016).

\footnotetext{
* Assistant Professor, Faculty of Law, University of Macau, China.
} 
This procedure was originally used by people with health conditions that could threaten their reproductive function, such as cancer patients who were scheduled to undergo radiation therapy, and it was later opened to other indications. Until recently, however, oocyte cryopreservation was rarely used because of its low success rate. In fact, due to the high water content of unfertilised oocytes, the chances of successful fertilisation were low. Through current scientific advances, specifically oocyte vitrification (Chian et al. 2014) this obstacle has been overcome, and oocyte cryopreservation has become a promising solution for women who wish to become pregnant at a later age.

Based on the current success of this technique, the European Society for Human Reproduction and Embryology (ESHRE) has recommended that oocyte cryopreservation to be made available to preserve fertility (ESHRE Task Force on Ethics and Law et al. 2012), and in 2013 two important American scientific societies, the American Society of Reproductive Medicine (ASRM) and the Society for Assisted Reproductive Technology, removed its classification as an experimental procedure (The Practice Committees of the American Society for Reproductive Medicine and the Practice Committee of the Society for Assisted Reproductive Technology 2013).

\section{Late Motherhood and the Limit of Reproductive Age}

The age limit for female reproduction has long been a widely debated issue. Although nature has established a natural limit to female reproduction, marked by menopause, scientific developments have been able to circumvent this biological limitation and allow women's reproductive age to be postponed in Western societies.

Nonetheless, many have argued that the law should establish a maximum age limit for the use of artificial reproductive techniques (ART). Curiously, that limit has generally applied only to women, not to men. Not only has society become accustomed to late paternity, but science also seems to indicate that special medical risks (e.g., premature births and various complications during pregnancy) exist for late motherhood but not for late fatherhood (Sauer 2015). These hazards make late motherhood an independent and direct risk factor. However, it has been assumed that late paternity does not pose any relevant health hazard to the offspring.

In addition to health risks, there have also been financial concerns whenever the procedure has been publicly funded. Under the National Health Service (NHS), access has usually been available only to younger women (Präg and Mills 2005: 10). Seemingly, the main aim of this restriction has been to rationalise the management of public money by solely financing treatments with a higher probability for success. Given that success decreases as a woman's age increases (Karimzadeh et al. 2008, National Center for Chronic Disease Prevention and

\footnotetext{
${ }^{1}$ Nonetheless, some studies (Frans et al. 2015: 91-93, D’Onofrio et al. 2014) also point out the risks involved in late paternities.
} 
Health Promotion 2014), the use of ART by older women has been discouraged. However, these conclusions can easily be overcome. ${ }^{2}$

First, most of the health risks attributed to late motherhood do not apply to women of advanced age as long as they do not use their own oocytes but resort instead to donated embryos or oocytes that were preserved from their youth. In fact, the most relevant obstacle to female reproduction has not been linked to the uterine environment, but to the ageing of the oocytes (Sauer et al. 1996). If this risk factor disappeared, the procedure would become similar to that used in younger women.

Second, whether the real cause of such hazards is the woman's chronological age or other variables, such as pre-existing diseases, obesity, excessive use of nicotine or socioeconomic factors, has been questioned (Bernstein and Wiesemann 2014: 287).

Third, the argument about rationalising public resources, always scarce, cannot be applied when women were willing to pay for the treatment themselves at private facilities. Accordingly, even if we conclude that the NHS should only cover reproductive treatments that are likely to have a higher chance of success (i.e., those in young and healthy patients) other candidates would still be able to use ART if they were willing to pay for it.

Fourth, the argument sometimes advanced, that orphanhood is a common result when reproduction occurs later in life, and this is true for both women and men. It actually makes more sense to apply this argument to men, because they have a shorter life expectancy than women. According to Eurostad data, "[1]ife expectancy at birth in the EU-28 was estimated at 80.9 years in 2014, reaching 83.6 years for women and 78.1 years for men" ${ }^{3}$ and if you look the last decade it is possible to conclude that life expectancy is growing for both genders, with a slight advantage for women. ${ }^{4}$

Finally, some have emphasised the benefits of late motherhood, for example, that the child is born into a more stable family environment, with better economic conditions (Goold and Savulescu 2009: 54). In effect, many older women have reached a higher professional status; they make more money and tend to have more stable personal lives.

In light of these arguments, the age during which women should be allowed access to ART has become the subject of debate. In Europe, the legal regime in this regard has varied widely; however, most countries have not fixed an age limit, if not for the general use of ART, at least for the use of ART within the NHS or its equivalent. Examples include the following.

In Belgium, Article $4^{5}$ of a 2007 law - the Law on Medically Assisted Reproduction and the Disposition of Supernumerary Embryos and Gametes $2007^{6}$

\footnotetext{
${ }^{2}$ Analysing and rejecting the arguments against late motherhood, Meyer 1997: 31. Still on this topic Fisher and Sommerville 1998: 203, Jackson 2001: 118.

${ }^{3}$ Retrieved from goo.gl/6rkrvR.

${ }^{4}$ Retrieved from goo.gl/6rkrvR.

${ }^{5}$ Recently amended, by a law dated 18 December 2016.

${ }^{6}$ Act respecting medically assisted procreation and the destination of supernumerary embryos and gametes, 6 July 2007 (goo.gl/DzDtuk).
} 
-provides that gametes may be taken from a woman until the day before her $46^{\text {th }}$ birthday (Article 4/1) and that a request for the implantation of embryos or insemination may be made by a woman until the day before her $48^{\text {th }}$ birthday (Article 4/2).

In the Portuguese context, Law no. $32 / 2006$, from $26^{\text {th }}$ June, on medically assisted reproduction, ${ }^{7}$ has not established a maximum age limit for either men or women. Nonetheless, an age limit has been set for women who want to receive reproductive treatments under the NHS. This has varied from 40 to 42 years in accordance with the technical specifications of the procedure in question.

Likewise, in Austria, no maximum age limit has been prescribed for the use of ART in the Austrian Reproductive Medicine Act, from the 1st of July 1992 and amended in 2004 and $2015 ; ;^{\circ}$ however, when patients have demanded publicly funded IVF-treatments, limits have been imposed. Specifically, women have been required to begin treatment before 40 years of age, and the male/female partner of the female patient must be under 50 years of age at that time $(\S 4(4) 1$, Austrian IVF-Fund-Act, version resulting from the 2015 amendment). ${ }^{9}$

Sometimes the limit has not been explicit but has resulted somehow from the law's content. For instance, the Spanish law on ART (Law n. 14/2006, from $26^{\text {th }}$ May, on techniques of human assisted reproduction) ${ }^{10}$ states in Article 3/1 that ART should only be used when there is a reasonable chance of success and when the procedure does not involve serious risk to the woman's physical or mental health. The aim of these prerequisites seems to be to exclude pregnancies in older women, because the rate of failure, and arguably the risk for these candidates, is higher. In addition, the use of NHS resources has been limited to women less than 40 years of age (Präg and Mills 2015).

Italian rules on medically assisted reproduction - Act Feb. 19, 2004, No 40 ${ }^{11}$ also refer, in its article 5, that candidates must have "potentially fertile age", seemingly excluding older women.

The Swiss law on assisted reproduction ${ }^{12}$ is similar in this regard. Although it does not state an explicit age limit, it does state that access to ART is only permitted for couples who, in light of their age and personal situation, are able to raise a child to adulthood (Article 3/2/b).

Likewise, Iceland has no age limit; however, according to Article 3 of Act n. 55/1996, on Artificial Fertilisation and Use of Human Gametes and Embryos for Stem-Cell Research, ${ }^{13}$ ART may only be carried out if "the woman is of natural child-bearing age and has the physical capability and sufficiently good health to cope with the strain of the treatment, pregnancy and birth of the child.

\footnotetext{
${ }^{7}$ Law no. 32/2006, of July 26 - Medically Assisted Procreation (goo.gl/IwLRfo).

${ }^{8}$ Federal Law: Reproduction Medication Act - FmedG as well as amendment of the general Bourgeois law, the marriage law and the standard of jurisdiction (goo.g1/L77ipP).

${ }^{9}$ Entire legal provision for IVF-Fonds-Gesetz, version of 22.04 .2015 (goo.gl/JcpFBy).

${ }^{10}$ Law 14/2006, of May 26, on techniques of assisted human reproduction (goo.gl/UJaNZP).

${ }^{11}$ Law 19 February 2004, no. 40, Medicaments Supported Procreation Standards, published in Official Gazette no. 45, 24 February 2004 (goo.gl/8mD0su).

${ }^{12}$ Federal Act on Medically Assisted Reproduction (Reproductive Medicine Act, RMA), of 18 December 1998 (Status as of 1 January 2013).

${ }^{13}$ Retrieved from goo.gl/FMGBHu.
} 
A factor to be taken into account is that the pregnancy and birth not to be expected to entail damaging consequences for mother or child, on the basis of normal medical and obstetric standards (NordFork 2015: 6)".

Swedish law does not really mandate an age limit, but it does impose the requirement that parental responsibilities must be carried out throughout childhood. An assessment of this must be done by a physician, expressly considering the couple's age (NordFork 2015: 6). ${ }^{14}$

There is also no age limit in Finland; however, according to the existing administrative orders, if a woman over 40 years of age intends to use public facilities, a medical statement is required declaring that her inability to have children has not been caused by age (NordFork 2015: 6).

\section{Arguments Against Oocyte Cryopreservation to Extend Fertility}

\section{Health Risks to the Woman and to the Offspring}

Although oocyte cryopreservation has become an increasingly common procedure, it also involves some risk (Platt et al. 2014: 3). The patient might suffer abdominal discomfort after the oocyte's removal, bleeding or ovarian infection. Later on there might be more serious risks, such as ovarian hyperstimulation syndrome due to the hormonal injections the woman has undergone, which in some cases can be fatal. Some studies have also suggested a connection between in vitro fertilisation and a rare form of ovarian or endometrial cancer, although some experts have argued that these effects could be due to pre-existing health conditions or even to lifestyle and not to in vitro fertilisation itself (Cetin et al. 2008).

Another source of concern relates to risks to the unborn child resulting from cryopreservation (The Practice Committee of the American Society for Reproductive Medicine, and the Practice Committee of the Society for Assisted Reproductive Technology 2008a, 2008b). However, this concern has mostly been eliminated. According to the currently available data, there is no longer any reason to be alarmed, because the assessment of children born after oocyte vitrification (the preferred technique nowadays because it causes less damage to oocytes) (Bernstein and Wiesemann 2014: 285) has not shown increased rates of chromosomal abnormalities or malformations when compared with those generated from fresh oocytes (Bernstein and Wiesemann 2014: 286, Wikland et al. 2010, Wirleitner et al. 2013). Furthermore, according to experts, increased danger has not been demonstrated in cases of vitrified oocytes. On the contrary, it could even be that early cryopreservation reduces the risk of chromosome aneuploidies and genetic aberrations (Liu and Case 2011).

\footnotetext{
${ }^{14}$ Regulations and Guidelines on the use of tissue and cells in health and medical care and in clinical research etc. (SOSFS 2009:32), Section 12 (Guidelines). Note that insemination or IVF may only be carried out if it can be presumed that the prospective child will grow up under good conditions. See Genetic Integrity Act, Chapter 6, Section 3 (Insemination); Chapter 7 , Section 5 (IVF); Regulations and Guidelines (SOSFS 2009:32), Sections $11 \& 12$.
} 
For all these reasons, in its recent guidelines on oocyte cryopreservation, the American Society for Reproductive Medicine concluded that the procedure is no longer at the experimental stage; data on the respective results can now be considered quite satisfactory, and it is considered a safe procedure (The Practice Committee of the American Society for Reproductive Medicine, and the Practice Committee of the Society for Assisted Reproductive Technology 2013).

\section{Late Reproduction as a Futile Whim}

Health risks have particularly been underlined by those who believe that to have children at a later stage is a whim that the law should not acknowledge (Dovey 2015). According to this perspective, if at some point in life a woman has given preference to her professional ambitions, later on she should not be entitled to use ART to reverse time. Socially grounded cryopreservation has been deemed less relevant than medical grounded cryopreservation. ${ }^{15}$

One can argue, however, that oocyte cryopreservation for social reasons is still based on medical motives, namely, the preservation of fertility. In a way, the preservation of oocytes at a younger age for use later in life can be seen as a form of preventive medicine, not that different from similar forms of protective medical care, such as receiving a vaccination.

In a more pragmatic tone, it should be noted that nowadays the labour market imposes great pressure on the employees. This pressure has been especially stressful for female workers confronted with the demands of pregnancy and raising children. ${ }^{16}$ Thus, it is no wonder that many women have decided, consciously or unconsciously, to postpone motherhood to a later stage in life; this decision can hardly be seen as voluntary, but should rather be viewed as imposed by today's world.

\section{Late Reproduction as Unnatural}

One classical criticism has asserted that late reproduction is unnatural (some may even say immoral) because it subverts the natural limit imposed on it. ${ }^{17}$ People are supposed to have children at younger ages (Zweifel 2015) so they can effectively take care of them, and this is the way (the only way) it should be.

However, the same could be said about people with serious diseases or handicaps that limit their parenting ability. However, it has been commonly accepted, and indeed it should be accepted, that these people cannot be prevented from having children. Thus, the problem is not an eventual parenting limitation, but the circumstances surrounding, i.e., the fact that in this case the woman herself has contributed to this limitation by her not having children at the "proper time".

\footnotetext{
${ }^{15}$ Contesting this understanding, Pennings 2013.

${ }^{16}$ See Rothman 1999: 631: "It is easier to blame the individual woman than to understand the political and economic context in which she must act (...) if we want to decrease infertility in part by having women concentrate in childbearing in their twenties and early thirties, we have to make that possible for them".

${ }^{17}$ This is an old argument, described in Fisseha and Clark 2014: 7.
} 
The contranatura argument is a curious remark, considering that the entire story of science and medicine has been based on the destruction of natural barriers. For instance, disease has been a natural obstacle to life maintenance that has been overcome by science through vaccinations, surgical interventions and drugs, all of which are "artificial" mechanisms used to control natural obstacles. Who dares to say these are unnatural? So, why this particular scientific technique should be considered unnatural?

\section{Benefits of Oocyte Cryopreservation}

\section{An Appealing Alternative to Oocyte Donation and Embryo Cryopreservation}

In the past, women who wished to have children at a later stage could only count on oocyte donation or embryo cryopreservation. ${ }^{18}$ However, both alternatives present some flaws.

\section{$\underline{\text { Oocyte cryopreservation versus oocyte donation }}$}

With regard to the oocyte donation, it is worthy of note that suitable donors have not always been available. ${ }^{19}$ Furthermore, in light of the restricted number of oocyte donations, it is doubtful that postmenopausal women would be allowed to use this scarce resource.

Another problem has been that in this hypothesis offspring would not have any genetic bond with the female parent, which for some women could be a relevant drawback. Conversely, by using their own oocytes, women guarantee their biological connection with the child.

\section{$\underline{\text { Oocyte cryopreservation versus embryo cryopreservation }}$}

Oocyte cryopreservation is also an alternative to embryo cryopreservation. In this case, the women's oocytes are extracted; they are then fertilised and the resulting embryos are cryopreserved.

The problem that could arise (and that has actually been addressed by many courts around the world) concerns the possibility for an eventual dispute over the power to decide the embryos' fate. In effect, unless a third-party sperm donor has been used, in most cases the sperm is provided by the woman's male companion. However, if the relationship between the two individuals ends before embryonic transference, chances are that the woman and her partner do not agree on what to do with the cryopreserved embryos. ${ }^{20}$ Faced with this conflict, courts have often decided in favour of the partner that has refused to use the embryos for reproductive aims (that is, who exercised the

\footnotetext{
${ }^{18}$ Other possible alternatives could be child adoption or the use of in vitro created gametes (Cutas and Smajdor 2015), but none of these possibilities are discussed in this study because the former is not related to reproductive techniques and the latter is still in a very experimental phase.

${ }^{19}$ Mostly because oocyte extraction is a technique that involves some health risks (Bernstein and Wiesemann 2014).

${ }^{20}$ Raposo (2008) describes these conflicts and suggests some possible solutions.
} 
right to not reproduce). This has frequently prohibited women from using their own embryos and has left them without any other opportunity to give birth to genetically related children.

It is not easy to reach a fair solution in these conflicts due to the many different values, rights and interests involved, sometimes in total opposition to each other (Raposo 2008, Raposo 2014: 872). On the embryo's side, there is the protection of its existence versus the prohibition against forcing a woman to receive an embryo into her uterus. On the parent's side, there is the right to reproduce versus the right to not reproduce. Finally, we still have to consider the proper legal classification suitable for the embryo, i.e., the status of the "person" versus the status of a "thing". The potential for disputes over the destiny of surplus embryos when parents have different opinions in this regard (especially in the case of divorce) can discourage embryonic cryopreservation and force to look for an alternative. In contrast, when oocyte cryopreservation involves only the woman's reproductive cells, there are no custody disputes. The decision-making power over the use of the cryopreserved oocytes resides exclusively with the woman.

Embryo cryopreservation also involves complex issues regarding the respect due to embryonic human life, because the most common end for surplus embryos that are not immediately transferred is destruction. This has raised concerns because of the respect due to the embryo as a form of human life. Criticism based on the protection to be provided to the embryo in the very first stages of its existence has become a recurring obstacle to embryonic cryopreservation. Some laws have provided that embryos, even in their very early stages, are people and deserve the same kind of respect as human beings that have been born, namely the right to life. In this view, to destroy an embryo has been equated to a kind of homicide. For this reason, there are thousands of cryopreserved embryos around the world that no one has dared destroy.

In fact, the legal (as well as ethical and philosophical) status of an embryo has been widely discussed, particularly with regard to whether it is a person or a thing. The extreme complexity of this issue has been derived from the terminological poverty of the legal world, which has historically only known two realities, the person and the thing, neither of which really fits the unborn and its specificities. To take a position on this matter, the law must accept the conclusions reached by biology, according to which from the moment of fertilisation a new human life is created.

Therefore, in this paper the embryo is characterised as a human being. This conclusion, however, is not the equivalent of considering it to be a person, because these are two distinct concepts. I assert, in line with many other scholars, that embryos (and foetuses) are not present persons, but potential persons. ${ }^{21}$ Nonetheless, they are not things either. On the contrary, they are so-called tertium genus, ${ }^{22}$ that is, something in between a person and a thing. Although the tertium genus classification does not afford the unborn the same legal protection guaranteed to a human person, it undoubtedly provides it with legal protection substantially superior to that provided to mere things. Thus, the destruction of

${ }^{21}$ A position that I sustained especially in Raposo 2014: 512. Also, in this sense Beriain 2003: 113.

${ }^{22}$ About the tertium genus, Coleman 2004. 
embryos has raised concerns unknown in the case of objects, and both embryo cryopreservation and the potential destruction of (at least some) embryos has been problematic from both legal and ethical standpoints. It should also be stressed that even though the embryo is a form of human life, the fact is that the protection provided to unborn human life cannot be as stringent as the one provided to born human life; and within the framework of an unborn human life, the in vitro embryo's protection cannot be as strong as the one due to the uterine embryo and, a fortiori ad mainus, also not as strong as the one provided to the fetus, which represents a higher stage of development. ${ }^{23}$

These complex ethical issues, however, have no place within the ethical and legal assessment of the destruction of cryopreserved oocytes. Oocytes are obviously not people, not even intermediary entities (the already-referenced tertium genus), but they are things, just like any other cell in the human body. In fact, if any cell of the human body is legally considered a thing, the gamete, as a sexual cell, cannot have any other legal classification. Of course, human cells deserve a higher status than other things, an idea that has excluded them from any kind of transaction (except for some organ donations, under restrict requisites), but still they are things. Therefore, many of the legal and ethical objections pointed out as relating to embryo cryopreservation are not valid for oocyte cryopreservation.

\section{Fulfilment of the Female's Right to Reproduction}

In the context of women's rights, this practice has been viewed from two opposing quarters. On the one hand, there are those who have defended oocyte cryopreservation based on its contributions to female empowerment, providing women with the freedom to pursue professional careers without being bound by constrains of female fertility and the pressure to find a "prince charming". Under this reasoning, oocyte cryopreservation fulfils reproductive autonomy and reproductive rights, giving women the freedom to choose when to have children and providing them with the same kind of reproductive emancipation offered by contraceptives some decades ago (Wolff et al. 2015: 30).

On the other hand, some scholars have argued that oocyte cryopreservation aims to provide a scientific solution to a problem that is actually a social one that demands a social change related to a woman's role at work and in society in general (Shkedi-Rafid and Hashiloni-Dolev 2012). The solution might be to offer women more opportunities to reconcile their families and careers and to fight against labour discrimination, especially with regard to women's childbearing age. Ironically, the famous question asked in employment interviews, "do you intend to have children", although forbidden in theory, is still frequently put to women, as if pregnancy and child-raising are female handicaps. Following this line of reasoning, by allowing and encouraging oocyte cryopreservation, the law is recognising that having children delays a woman's progression in the professional world so that oocyte cryopreservation actually strengthens and perpetuates this problem. It has even been argued that the widespread use of this practice increases

${ }^{23}$ Regarding the gradual protection provided to the unborn, see Raposo 2014: 521, Romeo Casabona 2003: 30-31. 
the pressure on women to give in to this alternative and postpone reproduction, rendering this measure counterproductive.

Both arguments make good points, and in fact the legal assessment of oocyte cryopreservation is far from simple. The duality of female fertility versus work competitively demands a solution that will enable women to have children when it is most convenient for them without abdicating any professional ambitions or other projects they might have. However, the possible solutions made available to women should be by choice, not by the imposition of external pressure to postpone pregnancy just because it is now possible to have children later in life.

\section{Issues to Be Discussed regarding Oocyte Cryopreservation}

\section{Time Limit for Oocyte Cryopreservation}

In most cases, not all cryopreserved oocytes are used for reproductive aims. Thus, the law should establish the uses available for surplus oocytes, as it does for surplus embryos. The first issue that requires clarification is to determine when an oocyte can be considered "surplus", which in turn depends on the maximum time limit for cryopreservation.

In general, there has been no maximum time limit for oocyte cryopreservation like there has been for embryo cryopreservation. For instance, in the Portuguese legal order, the law regulating assisted reproduction (Law 32/2006, from $26^{\text {th }}$ July, on medically assisted reproduction) does not establish a maximum period for oocyte cryopreservation. However, the authority in charge of controlling the uses of ART, the Conselho Nacional de Procriação Medicamente Assistida (CNPMA), ${ }^{24}$ has stated that the provisions of Law 32/2006, Article 25, forbidding embryo cryopreservation for more than 3 years, should be applied in this context. If that is the case, oocytes can remain cryopreserved for a period of 3 years, after which the woman can renew her consent to prolong the cryopreservation period. Strictly speaking, the law does not provide for the possibility of extending the initial period. However, under the CNPMA interpretation, it could apparently be renewed for the same period, with the express authorisation of the gametes' holder.

Notwithstanding the foregoing, several issues still remain to be clarified: How many renewals would be admissible? Could the renewal indicate a different time period than the one stipulated by law? What would happen if, after the maximum time period, the holder of the gametes says nothing? In light of the existing legal framework, none of these issues has had a clear resolution, given that the courts and legislature have been silent in this regard.

\footnotetext{
${ }^{24}$ National Council for Medically Assisted Rerproduction. Retrieved from goo.gl/5JuP4m.
} 


\section{Death of the Oocytes' Holder}

The law should clearly define the maximum cryopreservation period for the gametes. If the period has expired, or the holder of the gametes has stopped paying the cryopreservation fee or has died, the gametes should be destroyed.

In case of death, whether gametes can pass by inheritance has been a subject for discussion. Gametes have not generally been susceptible to succession because even though they are things they have a special status. Nonetheless, in the case Hecht v. Superior Court, the California Supreme Court ${ }^{25}$ considered sperm to be part of an inheritance. The case concerned the will of a Mr. Kane, who, before committing suicide, assigned to his girlfriend, Ms. Hecht, the sperm he had previously frozen in a sperm bank so she could still have his child. However, a dispute arose between Ms. Hecht and Mr. Kane's adult children, who were concerned that a new heir might disturb their inheritance. Both parties disputed the sperm: the sons of the diseased wanted the sperm destroyed, while Ms. Hetch wanted to be inseminated with it. The court concluded that the sperm was part of the inheritance and that at the time of his death the deceased had a relevant interest in deciding its destination based on his ownership of the sperm.

This conclusion could hardly have been reached under European continental law, in which body parts (in general, including cells and body fluids) have commonly been excluded from transaction, including succession (Brazier and Ost 2013: 61). Given that under the general principles of European continental law genetic material is not capable of transmission by succession (because people cannot dispose of their genetic material), relatives cannot use the oocytes of a diseased woman. This has been true even with regard to the parents of minors, even because in such a case it could amount to a covert form of birthing a grandchild regardless of the deceased daughter's wishes.

There have also been reports of widows who have been granted power over the sperm of a deceased husband to use it for reproductive purposes (post-mortem reproduction). ${ }^{26}$ However, none of those decisions has considered sperm as a part of inheritance, on the opposite; they based their reasoning on the utility of the sperm to fulfil the common reproductive aspirations of the couple.

Conversely, there have been no reports of oocytes being used after a woman's death, because in that case it would have been necessary to resort to surrogate motherhood. There are two requirements for this solution: first, that surrogacy is allowed; and second, that post-mortem reproduction is also allowed. Both of these procedures, or at least one of them, have been banned in several legal orders. So, it might be difficult to allow the post mortem use of oocytes by the female's partner.

\section{Oocyte Donation (in Life or After Death)}

If a woman has not used all of her cryopreserved oocytes, a good solution for the surplus is to donate them to third parties: infertile women, women with genetic

\footnotetext{
${ }^{25}$ Hecht v. Superior Court, 20 Cal. Rptr. 2d 275 (Cal. App. 1993).

${ }^{26}$ A report of some of these cases is in Dantas and Raposo 2012.
} 
health conditions or other women in need. The legality of this practice depends on the consent of the oocytes' holder. Thus, donations have only been allowed in cases in which a woman could provide her free and informed consent.

Oocyte donation has not followed the same rules as organ donations, given that gametes can shape the genetic code of a future person. Due to the genetic and emotional load that the gametes imply, this kind of donation requires specific consent. There has however, been no obstacle to a donation when the woman is still alive. This kind of donation has simply followed the general rules for gamete donations that are universally in place, addressing concerns such as anonymity, the altruistic or profitable nature of the donation and the possibility of revoking the donation to receive the oocytes back. Post-mortem oocyte donation, in contrast, has only been accepted in cases in which the holder had previously provided informed consent in the event of donation after death.

In Portugal, the extension of the general regime of post-mortem organ donation to post-mortem oocyte donation would be particularly problematic, because in the Portuguese legal order the "dissent rule" is in place. That is, everyone is prima facie considered to be an organ donor, unless they expressly and formally register the desire to withhold the donation of their organs. ${ }^{27}$ It is to conclude that this legal solution could be very problematic when applied to gametes, strongly justifying the need to create a special regime for post-mortem gamete donation, stricter than the one implemented for post-mortem organ donation.

\section{Oocyte Destruction}

One issue that arises pertains to the legal consequences of the possible destruction of oocytes' while they are in the custody of the gamete bank or clinic. Of course, oocytes that have not been used must be destroyed at some point. However, when it comes to destruction, some caution is required to ensure that the holder of the gametes no longer has a relevant interest in them.

In 1993, the German Supreme Court (BGH) heard the complaint of a man whose sperm had been carelessly destroyed by the sperm bank at which he had previously stored it for health reasons. ${ }^{28}$ The plaintiff sought damages of at least 50,000 German marks, alleging the impossibility of having children genetically related to him and his psychological distress caused by it. This lawsuit generated intense discussion over the kind of power a person has over his or her own cells, fluids and body parts and whether ownership of these parts depends on whether they are still attached to the human body.

\footnotetext{
${ }^{27}$ For a description of the Portuguese legal regime in this regard, Patrício 2013.

${ }^{28}$ BGH, VI ZR 62/93, de 09/11/1993. These are the facts: In 1987 a thirty-one-year-old man (the plaintiff) deposited his sperm in a bank due to the predictable infertility that would result from a treatment for bladder cancer. A couple of years later the bank informed him by registered letter that if he did not confirm his desire to continue storing the sperm, the sperm bank would destroy it within a month because of storage difficulties. Although the plaintiff replied, requesting maintenance of the sperm, the sperm was eventually destroyed, leaving the plaintiff and his wife without any chance of having children biologically linked to both of them.
} 
There are several dogmatic perspectives related to the destruction of body parts. It can be viewed as property destruction, a bodily offense, and a violation of reproductive rights. In the end, the German Court ruled against the clinic and ordered it to pay compensation to the defendant on the grounds that he had suffered a violation to his body. This ruling was based on the union between separated body parts and the body whenever those parts are expected to be reintegrated with the body. In the case of sperm, clearly it is not expected to return to the plaintiff's body; however, because it that case it was intended to be used in the bodily function of reproduction, the court considered it to be a part of the body. ${ }^{29}$ In the case of oocytes, the issue is less complex, because oocytes are intended to be reintegrated into the woman's body, unless there is intervention from a surrogate, in which case the legal reasoning is very similar to the one pronounced by the German Court: that even if the gametes are not inside the woman's body they will eventually be used in a bodily function.

Interestingly, the German case could have been resolved on different grounds, that is, the violation of reproductive rights. Due to the destruction of his sperm, the plaintiff lost any opportunity to create genetically related offspring. So far, German courts have not recognised compensation for moral damages when the case has involved interests and rights related to family planning. Nonetheless, if a similar case were to arise in a different venue, it is entirely likely that damages would be awarded for violating the right to reproduce.

\section{Patients' Informed Consent}

It is imperative that women interested in oocyte cryopreservation are informed of the nature, costs and risks of the procedure, the conditions under which their oocytes can be stored, the time within which they can be used and the other alternatives that are available (for instance, the use of donated oocytes, cryopreservation of ovarian tissue or embryos), among other information deemed relevant under the circumstances (The Practice Committee of the American Society for Reproductive Medicine, and the Practice Committee of the Society for Assisted Reproductive Technology 2008b). For example, the hormone stimulation that precedes oocyte collection involves minimal risk (less than $1 \%$ of complications such as bleeding or ovarian cancer) (Bernstein and Wiesemann 2014: 284), but not an absence of risk, for

\footnotetext{
$29 " .$. The provisions of $\S 823$ I BGB protect the body as the basis of human personality. In view of modern medical possibilities and in respect of the body as object of the protected right, a person's right for self-determination, emanating from his right of personality, acquires additional significance. ... Where, with the consent of the person affected, parts of a body are taken out in order to later on be re-implanted as a means of preserving or improving bodily functions, the legal opinion that $\S 823$ I BGB comprehensively protects corporeal integrity in order to guarantee a person's right to self-determination will lead to the following result. In view of the protective purpose of this paragraph, these extracted parts continue to form a functional unity with the remaining body even during their separation from it. It therefore seems necessary to classify the damage to or destruction of such extracted body parts as a physical injury in the sense of $\S \S 823 \mathrm{I}$, 847 BGB. The result is different where, according to the wishes of the person concerned, the separated parts of his body are not intended to be used or re-integrated at a later stage" (Translated by Mrs Irene Snook, from the German Law Archives, at goo.gl/wMk9jj).
} 
the expectant mother or the embryo. Nevertheless, such risks are rarely communicated to the patient or the donor. This omission constitutes a failure of informed consent that may result in liability for injuries resulting from failure to communicate to the patient a risk whose knowledge was essential for patient's informed consent (Raposo 2013).

The degree of pregnancy success resulting from this procedure is also a matter in which information flaws have been detected (ESHRE Task Force on Ethics and Law et al. 2012). Frequently, clinics have failed to report that oocyte cryopreservation does not have an absolute guarantee of success. Even with fertile couples, the probability of a woman becoming pregnant after one month of unprotected sex is only $15 \%$ to $20 \% .^{30}$ The use of ART has produced quite satisfactory results, but these results have tended to fall below patients' expectations, especially when oocyte cryopreservation has been involved, because it adds additional complexity to the entire procedure (Solé et al. 2013). In the absence of information, many women might enjoy a false sense of security about their reproductive potential, discouraging them from finding other ways to have children at an earlier age.

To avoid controversy in light of the existing legislation, patients must be informed of the legal risks and the limitations involved. The information made available should not be limited to the technical and medical aspects of the procedure, but should also extend to its legal framework. In effect, when there is no express authorising norm, it is unclear whether oocyte cryopreservation exclusively aimed at fertility maintenance is permitted by law and the conditions under which women are allowed to use cryopreserved oocytes. The uncertainly surrounding the legal regime on this matter should also be communicated to the patient.

The financial aspects of the procedure should also be communicated because this might discourage some potential candidates. Actually, given the monetary amounts involved, ${ }^{31}$ the procedure has been much more accessible to celebrities than to ordinary women. ${ }^{32}$

\section{Legal Requisites that May Prevent Women from Using Cryopreserved Oocytes}

Several requirements imposed by law could prevent women from using their previously cryopreserved oocytes (unless, of course, it is expressly allowed by law). These legal limits could, for example, relate to age. As already referenced, several national laws have established a maximum age limit for using ART. This is the case of Belgium and Austria, and of those countries that require implicit age limits, such as Spain, Swiss, Iceland and Sweden (see the chapter describing the European national regulation in this regard).

\footnotetext{
${ }^{30}$ Retrieved from goo.gl/udojsp.

${ }^{31}$ Between US \$ 10,000 and US \$ 15,000 in addition to an annual storage fee of \$ 500 .

${ }^{32}$ Curiously, it has been news about celebrities such as Sofia Vergara (goo.gl/kjiVJf) and Kim Kardashian (goo.gl/mpYD5E) that has placed this procedure under the spotlight.
} 
In cases in which the law has only imposed an age limit to begin the procedure, there is no impediment, because the procedure (i.e., the extraction of the oocytes) has taken place earlier in life; whereas when the age limitation applies to embryo uterine transference, it could actually operate as a barrier to the use of cryopreserved oocytes.

Other possible obstacles pertain to limitations related to one's civil status. Many laws have only made ART available to married couples, or at least to people in de facto relationships. The existence of a heterosexual couple is required (Präg and Mills 2015: 289), for instance, by article 5 of the Italian law on assisted reproduction (Legge 19 febbraio 2004, no. 40), by article L2141-2 of the French Code of Public Health ${ }^{33}$ (Code de la Santé Públic), as modified by the 2004 Law on Bioethics (Law no. 2004-800 of 6 August 2004 on bioethics ${ }^{34}$ ), by article 5 of the Slovenian Law on Infertility Treatment and Procedures and Assisted Reproduction Techniques (Zakon o zdravljenju neplodnosti in postopkih oploditve $\mathrm{z}$ biomedicinsko pomočjo, ZZNPOB), from $2000,{ }^{35}$ and article 3 of the already mentioned Suisse law on assisted reproduction (FMedG). However, some women decide to cryopreserve their oocytes when they are single and sometimes they plan to use them as a single person. It is unclear when the marriage requirement should be imposed: at the moment the oocytes are cryopreserved; at the moment they are fertilised; or only when the actual embryos are transferred to the woman. The first interpretation is the most restrictive and is actually excessive in light of the purpose of the requirement, which is to prevent monoparental families. However, even the more open interpretation (the last one) could become an obstacle in cases in which the woman remains single.

One decisive obstacle has related to the demand that particular conditions be imposed for the use of ART. Most laws, for example, have only made ART available in cases of infertility or in situations in which there has been a risk of transmitting a serious medical condition to offspring. This is, for instance, the case of the Italian law, the already referred Act Feb. 19, 2004, No 40, in its articles 2 and 4, and of article L2141-2 of the French Code of Public Health.

Where does oocyte cryopreservation for extending fertility fit within this set of conditions? When cryopreservation has been motivated by the intention to preserve fertility in anticipation of a medical threat (for instance, because the patient is going to undergo radiation treatment), it has been commonly accepted. Problems arise, however, when cryopreservation is aimed to delay the timing of reproduction without any underlying medical motivation. The second case can result in one of two scenarios. If the woman has already become incapable of conceiving "naturally" due to her age and she requires the use of cryopreserved oocytes, this might be considered a form of infertility, even though the classification of menopause as a form of infertility is widely debated. ${ }^{36}$

\footnotetext{
${ }^{33}$ Retrieved from goo.gl/zBAhRf.

${ }^{34}$ Retrieved from goo.gl/iW4DDy.

${ }^{35}$ Retrieved from goo.gl/nDMcTt.

${ }^{36}$ In Portugal Deliberation n. 03/II, July 19 2013, from the CNPMA states that "in the light of the provisions of Article 32 of art. 4 of Law no. 32/2006, of July 26, the couples in which the woman reached menopause at the usual age are not attainable for the application of the PMA techniques".
} 
Alternatively, if the woman is still able to conceive naturally, but prefers to use cryopreserved oocytes because they are more fit for reproduction than the oocytes she can still produce, the use of cryopreserved oocytes will probably be denied. However, an exception might be found for cases in which the woman is able to procreate by her own means but doing so will entail increased risk to the offspring. This would especially be true for syndromes related to abnormal chromosome numbers (so-called trisomy), which would justify the use of the cryopreserved oocytes on the ground of preventing disorders in the offspring.

Despite these possible interpretations, the fact remains that menopause hardly ever fulfills the infertility requirement. Therefore, it could be argued that women should bear the consequences for allowing time to pass without using their natural reproductive resources. ${ }^{37}$ In other words, they have "become" voluntarily infertile and should not be allowed to use scarce medical resources ${ }^{38}$ (especially those subsidized by the NHS). What can be questioned - and it was indeed questioned (Rothman 1999: 631) - is if the postponing of reproduction is actually a voluntary decision, or if in some situations it is imposed by constrains that still persist at the work market.

\section{Should Embryonic Cryopreservation Become a Regular Reproductive Procedure?}

It has long been believed that biology prevents a woman from conceiving after a certain age. Technological advances in reproductive medicine have extended fertility, but some limitations, both of a scientific nature (in terms of levels of success) and of a legal nature (particularly the legal framework), have not accompanied this advancement.

Despite these limitations, and the aforementioned risks and critics, it is possible to believe that this practice will become an increasingly accepted method of preserving fertility (Goold and Savulescu 2009).

Nevertheless, its benefits cannot hide the caution that must be taken and the requirements that should surround it in every circumstance. Legislative bodies should expressly address issues such as the maximum period of cryopreservation, the possible alternative uses of oocytes that are not used by the woman for her own reproduction, the information to be communicated to the patient and the legal requirements under which the cryopreserved oocytes can be used.

The requirement of informed consent stands as one of the most pressing legal issues for consideration. The decision to cryopreserve oocytes for reproductive purposes at an older age should be freely and consciously made by each woman in an informed way. This means that women should be made fully aware of the medical risks, technical pitfalls, legal limitations and chances of success. The transmission of messages that include false expectations might

\footnotetext{
${ }^{37}$ In this sense, the Ethics Committee of the American Society for Reproductive Medicine 2013 and the Ethics Committee of the American Society for Reproductive Medicine 2016.

${ }^{38}$ In the opposite sense, arguing in favour of postmenopausal women allowed to use ART, Ekberg 2014.
} 
not be innocent given that ART is a lucrative procedure used by reproductive clinics that are eager to "promote" new reproductive services.

Until now the legal framework of this practice remains blurred: it is not expressly forbidden nor expressly authorised, and the lack of any regulation leaved many issues unsolved. But because it involves so many risks and controversies it is temerarious to initiate an oocyte cryopreservation procedure without knowing in advance its legal requirements and legal consequences.

Recently, the main focus of discussion has been on the promotion of oocyte cryopreservation by big companies such as Facebook and Apple, ${ }^{39}$ which have publicly announced their willingness to finance the procedure for their employees. The motives behind this offer, however, could be viewed as dubious. On the one hand, this offer can be seen as a way of making available an efficient solution to allow ambitious and hardworking employees to fulfil their reproductive wishes without putting aside their professional progression. Women who otherwise would probably not have any children because of their willingness to postpone motherhood, even at the expense of raising a family, would be able to have children later in life. But on the other hand, this practice can be understood as placing illegitimate pressure on women to delay motherhood against their will and consequently, pressure them to become more productive and available workers. Only time will reveal the real economic consequences of oocyte cryopreservation for these companies, in addition to the consequences for the women's family life and progression at work.

In sum, oocyte cryopreservation is not immune to criticism, and it should be recognised that even though it is still a kind of novelty, some of its potential dangers are known. Nonetheless, in the future oocyte cryopreservation could prove to be the last frontier in terms of reproductive self-determination. However, this scenario can only be achieved if the law provides a clear framework to it.

\section{Acknowledgments}

This work was supported by the University of Macau Multi-Year Research Grant MYRG2015-00007-FLL (Reproductive issues: juridical contextualization of reproductive techniques, genetics and new medical technologies. Some lessons from other legal orders).

The author wishes to thank Caroline Voithofer, Roberto Andorno, Titti Mattsson, Herman Nys and Alexander Schuster for their assistance regarding national legal regimes.

\section{References}

Argyle CE, Harper JC, Davies MC (2016) Oocyte Cryopreservation: Where Are we Now?. Human Reproduction Update 22(4): 440-449.

Beriain IM (2003) Necesidad de Redefinir el Embrión Humano (Need to Redefine the Human Embryo). In N Martínez Morán, CM Romeo Casabona, B de Castro Cid,

\footnotetext{
${ }^{39}$ Retrieved from goo.gl/DXf1vQ.
} 
J Ayllón, I de Miguel Beriain (Eds.), Biotecnologia, Derecho y Dignidad Humana (Biotechnology, Law and Human Dignity) (105-135). Granada: Editorial Comares.

Bernstein S, Wiesemann C (2014) Should postponing motherhood via "social freezing" be legally banned? An ethical analysis. Laws 3: 282-300.

Brazier M, Ost S (2013) Bioethics, Medicine and the Criminal Law. Cambridge: Cambridge University Press.

Cetin I, Cozzi V, Antonazzo P (2008) Infertility as a cancer risk factor-a review. Placenta 29: 169-177.

Chian R-C, Wang Y, Li Y-R (2014) Oocyte vitrification: advances, progress and future goals. Journal of Assisted Reproduction and Genetics 31(4): 411-420.

Coleman S (2004) The Ethics of Artificial Uteruses-Implications for Reproduction and Abortion. England, USA: Ashgate.

Cutas D, Smajdor A (2015) Postmenopausal motherhood reloaded: advanced age and in vitro derived gametes. Hypatia 30(2): 386-402.

D'Onofrio BM, Rickert ME, Frans E, Kuja-Halkola R, Almqvist C, Sjölander A, et al. (2014) Paternal age at childbearing and offspring psychiatric and academic morbidity. JAMA Psychiatry 71(4): 432-438.

Dantas E, Raposo VL (2012) Legal aspects of post-mortem reproduction: a comparative perspective of French, Brazilian and Portuguese legal systems. Medicine and Law 31: 181-198.

Dovey D (2015, Feb 15) Pregnancy over 50: ethical considerations that must go into deciding when you're too old to give birth. Medical Daily. Retrieved from goo.gl/ MvyS9G.

Ekberg ME (2014) Assisted reproduction for postmenopausal women. Human Fertility 17(3): 223-230.

ESHRE Task Force on Ethics and Law, Dondorp W, de Wert G, Pennings G, Shenfield F, Devroey P, et al. (2012) Oocyte cryopreservation for age-related fertility loss. Human Reproduction 27: 1231-1237.

Ethics Committee of the American Society for Reproductive Medicine (2013) Oocyte or embryo donation to women of advanced age: a committee opinion. Fertility and Sterility 100(2): 337-340.

Ethics Committee of the American Society for Reproductive Medicine (2016) Oocyte or embryo donation to women of advanced age: a committee opinion. Fertility and Sterility 106(5): e3-e7.

Fisher F, Sommervlle A (1998) To everything is there a season? Are there medical grounds for refusing fertility treatment to older women?. In J Harris, S Holm(Eds.), The Future of Human Reproduction (203-220). Oxford: Clarendon Press.

Fisseha S, Clark NA (2014) Assisted reproduction for postmenopausal women. Virtual Mentor American Medical Association Journal of Ethics 16(1): 5-9.

Frans E, Maccabe JH, Reichenberg A (2015) Advancing paternal age and psychiatric disorders. World Psychiatry 14(1): 91-93.

Goold I, Savulescu J (2009) In favour of freezing eggs for non-medical reasons. Bioethics 23: 47-58.

Jackson E (2001) Regulating reproduction: law, technology and autonomy. Oxford: Hart Publishing.

Karimzadeh MA, Ghandi S, Tabibnejad N (2008) Age as a predictor of Assisted Reproductive Techniques outcome. Pakistan Journal of Medical Science 24(3): 378-381. 
Leridon H (2004) Can assisted reproduction technology compensate for the natural decline in fertility with age? A model assessment. Human Reproduction 19: 1548-1453.

Liu K, Case A (2011) Advanced reproductive age and fertility. Journal of Obstetrics and Gynaecology Canada 33(11): 1165-1175.

Meyer C (1997) The wondering uterus: politics and the reproduction of women. New York, London: New York University Press.

National Center for Chronic Disease Prevention and Health Promotion - Division of Reproductive Health (2014) Assisted Reproductive Technology 2012 - Fertility Clinic Success Rates Report. Retrieved from goo.gl/yybgdk.

NordFork (2015) Legislation on Biotechnology in the Nordic Countries - An Overview. Retrieved from goo.gl $/ \mathrm{j} 8 \mathrm{n} 8 \mathrm{~Tb}$.

Patrício M (2013) Notas sobre o regime legal dos transplantes em Portugal (Notes on the legal regime of transplants in Portugal). RIDB 2(11): 12881-12900.

Pennings G (2013) Ethical aspects of social freezing. Gynécologie Obstétrique \& Fertilité 41(9): 521-523.

Platt I, Chen C, Mazzucco AE (2014) Delayed childbearing: Should women freeze their eggs?. National Center for Health Research. Retrieved from goo.gl $/ \mathrm{kp} 55 \mathrm{zn}$.

Präg P, Mills MC (2015) Assisted reproductive technology in Europe. Usage and regulation in the context of cross-border reproductive care, Families and Societies. Working Paper Series no. 43: 10. Retrieved from goo.gl/RSul6i.

Raposo VL (2008) O dilema do Rei Salomão: Conflitos de vontade quanto ao destino dos embriões excedentários (King Solomon's Dilemma: Conflicts of Will as to the Fate of Surplus Embryos). Lex Medicinae 5(9): 55-79.

Raposo VL (2013) Do Ato Médico ao Problema Jurídico (Breves Notas sobre o Acolhimento da Responsabilidade Médica Civil e Profissional na Jurisprudência Nacional) [From the Medical Act to the Legal Problem (Brief Notes on the Reception of Civil and Professional Medical Liability in National Jurisprudence)]. Coimbra: Almedina.

Raposo VL (2014) O Direito à Imortalidade (O Exercício de Direitos Reprodutivos Mediante Técnicas de Reprodução Assistida e o Estatuto Jurídico do Embrião In Vitro) [The Right to Immortality (The Exercise of Reproductive Rights through Assisted Reproduction Techniques and the Legal Status of the In Vitro Embryo)]. Coimbra: Almedina.

Romeo Casabona C (2003) El derecho a la vida: aspectos constitucionales de las nuevas tecnologías (The right to life: constitutional aspects of new technologies). In Asociación de Letrados del Tribunal Constitucional (Association of Lawyers of the Constitutional Court), El Derecho a la Vida, Actas de la VIII Jornada de la Asociación de Letrados del Tribunal Constitucional (11-54). Madrid: Centro de Estudios Políticos y Constitucionales.

Rothman BK (1999) Infertility as disability. In TL Beauchamp (Eds.), Contemporary Issues in Bioethics. Belmont: Wadsworth.

Sauer MV (2015) Reproduction at an advanced maternal age and maternal health. Fertility and Sterility 103: 1136-1143.

Sauer MV, Paulson RJ, Lobo RA (1996) Oocyte donation to women of advanced reproductive age: Pregnancy results and obstetrical outcomes in patients 45 years and older. Human Reproduction 11: 2540-2543.

Shkedi-Rafid S, Hashiloni-Dolev Y (2012) Egg freezing for non-medical uses: The lack of a relational approach to autonomy in the new Israeli policy and in academic discussion. Journal of Medical Ethics 38: 154-157. 
Solé M, Santaló J, Boada M, Clua E, Rodríguez I, Martínez F, et al. (2013) How does vitrification affect oocyte viability in oocyte donation cycles? A prospective study to compare outcomes achieved with fresh versus vitrified sibling oocytes. Human Reproduction 28: 2087-2092.

The Practice Committee of the American Society for Reproductive Medicine, and the Practice Committee of the Society for Assisted Reproductive Technology (2008a) Ovarian tissue and oocyte cryopreservation. Fertility and Sterility 90(5): S241S246.

The Practice Committee of the American Society for Reproductive Medicine, and the Practice Committee of the Society for Assisted Reproductive Technology (2008b) Essential elements of informed consent for elective oocyte cryopreservation: A Practice Committee opinion. Fertility and Sterility 90(5): S134-S135.

The Practice Committee of the American Society for Reproductive Medicine, and the Practice Committee of the Society for Assisted Reproductive Technology (2013) Mature oocyte cryopreservation: A guideline. Fertility and Sterility 99(1): 37-43.

Wikland M, Hardarson T, Hillensjo T, Westin C, Westlander G, Wood M, et al. (2010) Obstetric outcomes after transfer of vitrified blastocysts. Human Reproduction 25: 1699-1707.

Wirleitner B, Vanderzwalmen P, Bach M, Baramsai B, Neyer A, Schwerda D, et al. (2013) The time aspect in storing vitrified blastocysts: Its impact on survival rate, implantation potential and babies born. Human Reproduction 28: 2950-2057.

Wolff M, Germeyer A, Nawroth F (2015) Fertility preservation for non-medical reasons. Deutsches Ärzteblatt International 112(3): 27-32.

Zweifel JE (2015) Donor conception from the viewpoint of the child: positives, negatives, and promoting the welfare of the child. Fertility and Sterility 104: 513519. 